\title{
TEMPORAL-ASPECTUAL COMPLEX IN VERBAL FORMS OF ALBANIAN LANGUAGE
}

\author{
Alma Pinari (Kallari) \\ Tirana University \\ Faculty of Foreign Languages \\ Department of Slavic and Balkan Languages \\ Russian language Branch \\ e-mail: almapinari@gmail.com
}

DOI:10.5901/mjss.2014.v5n19p656

\begin{abstract}
Tense forms in Albanian language, (present, past, future) may be interpreted as such only in relation with the moment of speaking and when they respond to question when?: [she returns (when?) - on Saturdays; she returned [used to return] (when?) - every evening; she returned (when?) - last year; she is returned (when?) - today; she will return (when?) tomorrow]. In these cases, we may state that the above forms belong to present tense, past tense or future tense. The meanings of simultaneity, of past tense and future tense, expressed by them, comprise the real temporal semantics. But if the speaker or the writer would be interested not only in the tense when action is carried out but also in the way the process (action) is conducted, then the other meanings which overlap on tense form in certain speech context or situation cannot be considered as secondary meanings or as stylistic use of one form or the other, as they are interpreted in some cases in normative grammars. Different characteristics of verbal action that do not refer to the moment of speaking cannot be categorized as pure temporal semantics. The manner of presentation of development (course) of action or its distribution in time comprises the aspectual semantics, which stands on a language level other than temporal semantics. The scope of this study is semantic functional categories of temporality and aspectuality in Albanian language verb, which characterize the status and functioning of indicative tense forms. The study aims to throw light on semantic, functional organization of temporality and aspectuality categories in Albanian language, and linguistic means for their expression, to find and differentiate the real tense meaning from aspectual one in tense forms of Albanian language.
\end{abstract}

Keywords: Temporal semantics, aspectual semantics, semantic-functional category, temporality, aspectuality, tense scheme, etc.

In Albanian language the semantic-functional area of temporality (Pinari (Kallari) A., 2014) having a heterogeneous structure, with a clear grammatical nucleus, includes in itself many other linguistic tools as well that express time reports.

The grammatical nucleus of this area is the grammatical category of the verb, which represents in itself a system of verbal forms that counter each other and which express time ratio in relation to the time of speech or in relation to the time of the completion of another action (Gramatika e gjuhës shqipe 1,2002).

Albanian verbal system is presented with a wide variety of forms that belong to three time frames, the present, the past and the future.

The relatively large variety of tense frames of demonstrative manner finds its explanation in the fact that the modality of this manner has enabled the creation of formal and semantic counterpoint not only regarding tense but also in the aspectual level as well in the mode of action. Thus the respective forms of the present, of the past, of the future oppose each other mainly in the time aspect (Demiraj, Sh., 1985).

However, for Albanian language tense forms researchers, the semantic aspect of tense remains the most fundamental feature of the verb, therefore the structuring of this area starts from the grammatical category of the tense with the relevant counterpoints to other morphological, syntactic and lexical phenomena. Realization of a few meanings or undertones, different from the tense categorical meaning is related with broader semantically areas than morphological categories. These meanings are carried out not only by morphological counterpoints, but also by other means of diverse linguistic, syntactic, lexical areas or combinations thereof in context.

The core component of expressing temporality system as in most Indo-European languages, even in Albanian language, are special forms of the verb in three timeframes: (Now it's raining, it rained yesterday, and tomorrow will rain;).

In this paper it is described the semantics and the functioning of the grammatical verbal means of expressing time relations, organization of sintagmatic and morphological semantics of demonstrative manner in Albanian language. 
The plan to present carries out the categorical meaning of action simultaneity with the reference point (the time of speech). Present tense of demonstrative manner in the Albanian language verbal system consists of synthetic forms such as 'run' (he runs fast) and two types of analytical forms such as 'I'm running' (He is running towards us).

The difference between variants of the present tense (run /I'm running) is the semantic counterpoint of current action/non- current action (Pinari (Kallari), A., 2013). Such an interpretation justifies the linguists' conclusion that counterpoints in demonstrative manner tense forms serve to indicate not only the timing of an action, but the manner of the operation development and its actualization as well (Agalliu F.,1968).

The semantic potential of the synthetic form of the present tense regarding the paradigmatic viewpoint consists of the action decrease semantic (situation) with the moment of speech and the abstract action semantic (generalized), while in the plains of sintagmatic the action decrease is in a non concrete time of speech (generalized).

F.e: Every weekend we climb up to the Dajti mountain. The good weather can be noticed in the morning. $\mathrm{He}$ says the last word first. The mountains shake but do not fall. Children go to school every morning. This girl always recites nice. The granddaughter returns to her hometown every year.

The semantic potential of analytic forms, along with the action decrease in the time of speech, includes the features of the current action, localized in time, which is realized at the time of the speech, but in some uses it may not be confined within its bounds. Such a meaning of the analytic present tense is a combination of semantic features "concrete action", "action localized in time" with the feature " current action at the time of speech," thus which takes place at the speaker's time of speech lecture speakers, regardless of how long it lasts .

- What are you doing here alone? - I'm whirling aimlessly around the room, because I'm not sleepy.

At the synthetic present tense there is the features combination of "abstract action (non-concrete)", "nonlocalized timely action" with the feature of "non-current action at the time of speech." The above features, as content elements of present tense forms, are verified not only in the field of language as evidence of its structural organization, but also in the context where all components intersect and interact with other components of semantic categories. It is this combination of the above-mentioned semantic features complexes linguistic interpretation and their categorization.

Various efforts are made regarding the present tense of Albanian language (but also for other tenses of the demonstrative manner) to separate the timing meaning from similar other meanings, which different researchers have treated them in a imperfektiv or imperfect aspect or perfect or perfektiv aspect (Demiraj Sh., 1985 \& Riza., S. 1994 \& Dhrimo, A. 1996). Such an interpretation does not seem plausible:

From the abovementioned authors, as well from other, different features of verbal action as an ongoing action, action that lasts, repeated action etc., are unified by the notion of "aspect". But none of the abovementioned semantics is not part of grammar in Albanian language, thus these features should be classified as aspectual meanings belonging to verbal action modes (aktionsart), but not as genuine aspectual meanings.

The past plan is used for the expression of a fact (event, situation), which occurs before the time of speech.

More rich in grammatical forms is the past tense (Demiraj Sh.,1985), with its subdivision past simple, present perfect, past perfect and other past tenses (me se e kryer, e kryer e tejshkuar). The three first, the so-called absolute time of the past, express pre-timing in relation to the time of speech and hence oppose each other in aspectual area (Gramatika e gjuhës shqipe 1,2002). While the last two the so-called relative tenses of the past, that express pre-timing in relation to a particular moment of the past, do not have a clear semantic distinction between them. The semantic of the past tense is the semantic of precedence of the time of speech, which comes out in counterpoint with the present.

With aspectual meanings or connotations is generally understood the opposition perfektiv aspect/imperfektiv aspect.

In his fundamental work "Historical Grammar of the Albanian Language", prof. Sh. Demiraj regarding the opposition of present perfect / past simple distinguishes pure aspectual meaning (Demiraj, Sh., 1985). The past simple, according to the author, "aims to highlight the completion of the action at a particular moment of the past, thus it is characterized in perfektiv aspect", whereas the present perfect "presents the action in progress at a certain moment the past "(Demiraj, Sh., 1985), ie it is characterized by imperfektiv aspect". As for the counterpoint of the other past tenses the same author expresses that "it is less accessible and, therefore, more difficult to explain." Both these tenses present the action as completed before the time of speech, but if the verbal action expressed with past simple is not related to the time of speech, the action expressed by past perfect, because the consequences, does not cut ties with it. The author concludes that "past perfect is characterized by a synthesis of conduct aspect (completed action) and the imperfect aspect (the obtained state as a result of incomplete action)." At the aspect of mixed meaning, prof. Demiraj sees the difference between the past perfect and the other two forms of the past, past simple and present perfect.

Even other linguists that have dealt with verbal forms of the past, such as A. Dodi, F. Agalliu etc. (Dodi, A., 1968/1 \& Dodi, A., 1968/2) rightly conclude that the difference between the forms of the past time is not time, because all they show 
pre-timing regarding the time of speech. And according to them it is the aspectual component that enables the distinction of these forms from each other.

Putting at the core of the opposition past simple / present perfect the meaning of finished / unfinished action as aspectual basic nature of understanding, using the same aspectual terminology (perfektiv aspect, imperfektiv aspect), in a way parallels are drawn between the content of this confrontation and opposition perfektiv aspect / imperfektiv aspect as in

\section{Slavic languages ( $\Sigma$ asllov, J.S. 2004 \& Bondarko, A.V. 1975 \& Nils $\bullet$. Thelin, 1980 \&Comrie, B.,1976).}

Countering the past simple / present perfect can only be justified for the feature completed action / ongoing action and only for that group of verbs that express proper action conclusion. This opposition remains partial, incomprehensive. So, this counterpoint excludes other uses such as the meaning of the repetition of the action in the past, the meaning of the ordinary action etc.. Countering is isolated from cases that were discussed above, when the Albanian language past simple expresses not only unfinished action, but finished action as well (he call us every evening at home; She sent several messages a day).

From this point of view we think that for Albanian language would be more fair to be talked not about perfektiv aspect/ imperfektiv aspect, but about aspectual meanings by which we understand the features of continuity, duration, intensity, completion, repetition of action, etc., that are carried out in time forms conjunction with the vocabulary and context. Implementation of the above meanings or nuances, different from categorical meaning of time, is related to semantic aspectual area, thus in the manner of the course of action in time (Bondarko A.V. 1987). Obviously, different meanings or nuances that are derived from the interaction of the grammatical form, or context of a particular lexical class should be taken into account, but that does not mean that they should affect the grammatical form. It should be better differentiated the meaning of the form itself from other meanings realized in different contexts.

Regarding the forms of the past simple, they encourage the interlocutor (the reader) to think about a situation that has happened before the time of speech. In this sense the past simple involves clear time semantics. This composed form expresses " the value" that has the past action to the present and different from the present perfect, this form represents the fact that it is imposed as a given fact without any mediation of something else, without any particular characteristic of the fact the announced. Such a distinction is confirmed by the ability these forms have to be combined with time particles. Usually past simple is used together with lexical indicators such as yesterday, last year, in 1980 etc., which express specific time of action completion. These indicators are not characteristic forms of present perfect. Present perfect usually is used with indicators such as rarely, often, several times etc.

During the interpretation of the Albanian language past simple we forget for a moment that it is called perfect not in the time aspect (as present perfect and past perfect it is a past tense), but for its ties with the present through the consequences or outcome action. It is this feature that forms what we call perfector meaning of the past, different from the imperfector and aoristic meaning.

Even in relation to present perfect and past simple, the past simple does not form aspectual opposition. For illustration we bring a situation where we find the pre-timing used forms of the imperfect and the demonstrative manner. F.e: cameraman had filmed scenes of violence that appeared continuously before them.

In this sentence with two predicative unit it is present the opposition of past simple / present perfect (they filmed / appearing). This opposition can not be taken as aspectual opposition (perfektiv aspect / imperfektiv aspect) to the fact that the sentence functions in the context of the present morphological abstract, which entails a temporal meaning of the past simple. Verbal forms of the past simple (they filmed) realizes the meaning of perfect, while the imperfect form (appearing) shows an action with some acts (recurring), which precedes the time of speech and not connected with it. Even second predicative unit of this sentence (appearing) is characterized by aoristic meaning. Each of the scenes shown separately constitutes an act completed in the past. Both forms of the above tense realize the categorical meaning of pre-timing: forms of past simle (they filmed) realizes it in relation to the morphological context of the present abstract, while the imperfect form (appearing) - in relation to past simple.

Depending on the lexicon and grammatical features of verbs and the forms of imperfect context, the past simple, the present perfect and past perfect, besides the meaning of pre-timing in relation to the time of the speech, during their completion, have the ability to modify their meanings, and to express meanings such as: concrete action/action abstract (generalized); separate action / repeated action; completed action/action process (ongoing); Current action / noncurrent action; characterized by the extension action/its non extension etc.

All these features of verbal action in the past tense are aspectual components, which in relation to the temporal component of the past can be called secondary, irrelevant.

By perceiving the past simple, the present perfect and the past perfect as specific tenses of the past we leave out the attention the perfector meaning, aoristic or imperfector meaning and replace them with meanings of the past simple, 
present perfect and past perfect aspect, the aspect of mixed. To avoid this confusion of semantically different levels of language we would like to use the terms imperfector past, aoristic past, perfector past (Pinari (Kallari) A. 2014).

Citing in each subdivision the last term we note:

first, the temporal meaning of pre-timing, which is the only feature that is resistant to all three subdivisions of the past; second, the last term imperfector we mean a) that the instant precedes the time of speech , b) it has cut ties with the present and c) that can be localized or not in a given moment of the past;

third, the last term aoristic we consider an action a) that precedes the time of speech, b) that has cut ties with the present and c) in any event localized in a moment of the past;

finally, the last term perfector is understood as an action a) preceding the time of speech and b) that maintains links with the present.

Plan of the future: accurate description of future time appears difficult. Its semantics is to some extent conditioned by the hypothetical character of the future action and the modal connotations associated with the forms of this tense. The attempt to separate the "pure" future tense from the "modal" future remains subjective, unless there is precise criteria for such a division.

In the Albanian language subdivisions of the future plans, the future, the future of the past and other future tenses are independent forms, which in relation to the reference point have inherent differences in semantics between them. Regarding the time of the speech time relationship post-timing express only the forms such as will run (the real future) and I would ran (other future form). Two other forms will be running (past and future) and I ran (other future tense) are not related to the time of the speech. They express counter reports compared to the relative times of the past, and therefore are treated as forms of pre-timing or post-timing relationships of the event with the time of the next event (Pinari (Kallari) $A$. 2014).

The semantically contents of the proper future tense (to run) is characterized by a temporal feature of posttiming related to the time of the speech, which constitutes the dominant of this content. The post-timing temporal feature distinguishes the future time, the present and the past time.

Regarding other meanings of the future realized during its function (use), of its localization to the feature action limit, they coincide with aspectual meaning of the imperfector past or the aoristic past.

Besides any brief ascertainment (Riza, S. 1994), our linguistics so far did not find any special study for the aspectual semantics of the future forms.

We think that during the function of the future, in certain contextual circumstances, tense forms are overlapped by some other meanings that constitute its aspectual semantics.

Like the present perfect, the future forms may indicate:

- concrete separated actions;

- repeated actions;

- generalized actions .

But unlike the past said that expresses the ongoing action, the meaning of the ongoing action in the future tense in many cases is either missing, or is vague.

For example. Then I will take the silence of the ancient stairs and will descend slowly to the ground. (I. Kadare, Monster)\}.

It should be noted that in most cases, the realization of the many meanings of time, along with verbal forms, contextual element is used as well, and in most cases it is necessary. Therefore in the Albanian language, it would be better if we talk about the complex temporal-aspectual tools, which are linked by the function. These are the necessary elements to identify especially during the translation in various Languages where it is noticed a broad overview of the contextual elements, especially for languages that have verbal aspect, as in the case of Slavic languages, where a verbal form also carries another meaning that deals with the time for the interior. Only in this way it will become possible the delivery of these meanings from one language to another. However this is a question as fragile as it is broad, which will continue to be the subject of numerous studies in the future as well.

\section{References}

Pinari (Kallari) A. (2014) "Linguistic categorization of temporal tenses in the Albanian language compared to the Russian language". PhD work, Tirana, P. 100-101, 143-145.

Grammar of the Albanian Language 1 (2002), Academy of Sciences of Albania, Institute of Linguistics and Literature, Tirana, P.30, 274. 
Dhrimo, A. (1996), "Aspect and the verbal modes of tense actions in Albanian language", Publishing House "University Book", Tirana, P. 61, 70, 151-152

Dodi, A. (1968) "About the use of perfect tenses", Philological studies, 1968/1.

Agalliu, F. (1968) "Critical observations on the meanings of some tenses". Philological studies 1968/2, P.135.

Demiraj, Sh. (1985) "Historical Grammar of the Albanian Language", Tirana, P.713-715, 716, 722, 740.

Demiraj, Sh. (1971) "The main recent Meanings of the indicative form", Philological studies, 1971/4.

Bondarko A.V. (1987) Teoria funksionalnoy grammatiki. Vvjedenie v Aspektualnost'. Vremenaya llokalizovanost". Taksis. Leningrad.

Bondarko, A. V., Bullanin, LI. LI. (1967) "Russkij gllagoll”, Leningrad.

Bondarko, A.V. (1975), "O Vidah russkogo gllagolla”, Russkij Jazik za rubjezhom, No 5, Moskva, P. 63-65; .

Masllov, J.S. (2004), Izbranije trudi, Aspektollogija, Obshee jazikoznanie, Jaziki Sllavjanskoj Kulturi, Moskva.

Comrie, B. (1976), Aspect An Introduction to the Study of Verbal Aspect and Related Problems, Cambridge: Cambridge univ. Press.

Duchâcec O. (1966) "Sur le problème de l'aspect et du caractère de l'action verbale en français", Le Français modern, No 3. - P. 161-184.

Topalli, K.( 2010), Verbal system of Albanian language, Tirana;

Thelin, Nils B., (1980) "Aspekt und Aktionalität im Russischen", Die Welt der Slawen, Halbjahresschrift für Slawistik, XXV, 2; N. F. IV, 2, P.428-440. Verlag Otto Sagner, München;.

Riza, S. (1994), Verbal system of Albanian contemporary literary language, Academy of Sciences of Albania, Institute of Linguistics and Literature, Tirana, P. 116, 125. 